\title{
Quality of Growth in Exclusively Breast-Fed Infants in the First Six Months of Life: An Italian Study
}

\author{
PAOLA ROGGERO, MARIA L. GIANNİ, ANNA ORSI, PASQUA PIEMONTESE, ORSOLA AMATO, NADIA LIOTTO, \\ LAURA MORLACCHI, FRANCESCA TARONI, DAVID A. FIELDS, PATRICK M. CATALANO, AND FABIO MOSCA
}

\author{
Department of Maternal and Pediatric Sciences [P.R., M.L.G., A.O., P.P., O.A., N.L., L.M., F.T., F.M.], Fondazione IRCCS “Ca'Granda” \\ Ospedale Maggiore Policlinico, University of Milan, Milan 20122, Italy; Department of Pediatrics [D.A.F.], Children's Medical Research \\ Institute, University of Oklahoma Health Sciences Center, Oklahoma City, Oklahoma 73117; Department of Reproductive Biology \\ [P.M.C.], MetroHealth Medical Center, Case Western Reserve University, Cleveland, Ohio 44109
}

\begin{abstract}
Nutrition in early life, growth, and subsequent health over a lifetime are significantly interrelated. The aim of this study was to assess body composition changes in exclusively breast-fed infants from birth up to 6 mo of age. An observational, prospective, cohort study was conducted. Fifty-nine full-term, healthy, exclusively breast-fed infants underwent assessment of growth and body composition, using air-displacement plethysmograph (i.e. PEA POD) by Life Measurement, Inc. (Concord, CA). Body composition was assessed at birth, $2 \mathrm{wk}$, and 1,2, 3, 4, 5, and 6 mo of age. Mean birth weight $(\mathrm{g})$ and gestational age (wk) of the infants were $3170 \pm 420$ and $39.21 \pm 1.29$, respectively. Percentage of fat mass increased significantly over the first $4 \mathrm{mo}(p<0.001)$, both in boys and girls, with no differences detected between boys and girls at any time point. This article provides preliminary in-depth data on whole-body composition, in exclusively breast-fed infants during the first months of life. Further studies assessing larger sample sizes are desirable to develop reference body composition data. (Pediatr Res 68: 542-544, 2010)
\end{abstract}

$\mathrm{T}$ he crucial interrelation between early nutrition and subsequent health has been highlighted by several studies $(1,2)$. Small size at birth and a rapid catch up growth during infancy have been associated with an increased risk for developing the metabolic syndrome in adulthood (3-6).

Evaluation of infant body composition is valuable in assessing the quality of weight gain and represents a useful clinical tool for monitoring adequate physical growth and nutritional intervention in early infancy. Although the measurement of body composition in vivo has some limits, the clinical value of the outcome is greatly enhanced by the availability of reference data $(7,8)$. Certainly, body composition reference data (age and sex specific) are needed to accurately estimate the energy and nutrient requirements and to evaluate the normal growth and nutritional status of pediatric populations.

Fomon et al. (9) and Butte et al. (10) have published seminal work in reference body composition in early life. Reference data were obtained by calculations based on previously reported data in the case of Fomon et al. (9) and by using a four-compartment model to estimate body composi-

Received April 12, 2010; accepted July 27, 2010.

Correspondence: Paola Roggero, M.D., Neonatal Intensive Care Unit, University of

Milan, Via Commenda 12, Milano 20122, Italy; e-mail: paola.roggero@unimi.it

Supported by an unrestricted grant from the Life Measurement, Inc. tion in the case of Butte et al. (10). Subjects in both studies included both formula-fed and breast-fed infants $(9,10)$. The World Health Organization (WHO) promotes breast feeding as ideal for the nutrition of infants. Several studies have focused their attention on the growth of exclusively breast-fed infants, reporting a different growth trajectory from that of formula-fed infants $(11,12)$. However, studies assessing the quality of growth in exclusively breast-fed infants by using a whole-body composition method that is noninvasive, easy, and accurate are scarce. The aim of this study was to assess body composition changes by means of a pediatric airdisplacement plethysmograph, in exclusively breast-fed infants from birth up to 6 mo of age.

\section{METHODS}

This study was an observational, prospective, cohort study following up infants from birth to $6 \mathrm{mo}$ of life. This study is also a part of an ongoing larger multicenter study effort to develop local normative body composition data. Informed consent was obtained from the infants' parents, and the study design was approved by the Departmental Ethics Committee. ${ }^{1}$

Among all consecutive infants admitted to the same institution, a total of 59 infants were included in the study. Forty newborns were enrolled at birth. Nineteen infants were enrolled either at $2 \mathrm{wk}$ or $1 \mathrm{mo}$ of age, i.e., when their pediatric visits were scheduled. Inclusion criteria were singleton birth, fullterm infants [gestational age $\geq 37 \mathrm{wk}$ (259) d and $<42 \mathrm{wk}$ (294) d], birth weight $>2500 \mathrm{~g}$, Caucasian, born to nonsmoking mothers, and exclusively breast fed (according to the WHO's definition) (13) for 6 mo. Recruitment was also limited to infants born to mothers who remained in the same area/city/town where the study center was located for at least 6 mo. Exclusion criteria were infants having significant perinatal morbidity (i.e. cardiorespiratory illnesses), congenital malformations, chromosomal abnormalities, endocrinological and neurological disorders, infants born to mothers who had a history of diabetes, developed gestational diabetes, or had a history of maternal drug or alcohol use, and infants having health (i.e. chronic diseases that can negatively affect growth), environmental (i.e. monoparental family), and economic (i.e. unemployed parents) constraints on growth. The presence of the inclusion criteria and the absence of the exclusion criteria were checked before each body composition assessment by means of an accurate interview to the parents.

Anthropometric measurements and body composition were assessed at birth ( $3 \mathrm{rd} \mathrm{d}$ of life), $2 \mathrm{wk}$, and 1, 2, 3, 4, 5, and 6 mo. Body weight, length, and head circumference were measured according to standard procedures (11). Subject mass was measured on an electronic scale accurate to the nearest $0.1 \mathrm{~g}$ (PEA POD Infant Body Composition System; Life Measurement, Inc., Concord, CA), and body length was measured to the nearest $0.2 \mathrm{~mm}$ using a recumbent infant length board. Head circumference was measured to the nearest millimeter with nonstretch measuring tape. Body composition was

Abbreviations: FM, fat mass; FFM, fat-free mass 
assessed using an air-displacement plethysmography system (PEA POD Infant Body Composition System, Life Measurement, Inc.).

A detailed description of the PEA POD physical design, operating principles, and measurement procedures is provided elsewhere $(14,15)$. Briefly, the PEA POD assesses fat mass (FM) and fat-free mass (FFM) by the direct measurements of body mass and body volume and by the application of whole-body densitometric principles. Body mass was measured on the integrated electronic scale of the PEA POD. Body volume was measured in the test chamber of the PEA POD by applying gas laws that relate pressure changes to volumes of air in the enclosed chamber. The assessment of body volume took $2 \mathrm{~min}$. Body density was then computed from the study subject's measured mass and volume and then converted to percentage of FM (\%FM) using sex-specific equations by Fomon et al. (9). At the completion of testing, body composition variables were presented as $\% \mathrm{FM}$, absolute FM, and (FFM). The interobserver coefficient of variation for the percentage of FM estimates was $0.3 \%$. The maternal prepregnancy $\left(\mathrm{BMI}, \mathrm{kg} / \mathrm{m}^{2}\right)$ and gestational weight gain were collected as maternal variables.

Statistical analysis. Gender-specific anthropometric and body composition values are reported as mean $\pm \mathrm{SD}$. Differences between and among infants in repeated measurements of body composition parameters were assessed by an ANOVA. Only those measurements taken in the first 4 mo of life were included in the analysis because of the number of participants who were unable to complete measurements due to the size limitations of the testing chamber. Statistical significance was conducted at $\alpha=0.05$ level. All statistical analyses were performed using SPSS (version 12; SPSS Inc., Chicago, IL).

\section{RESULTS}

Growth and body composition were assessed in 59 (24 boys) infants. Mean birth weight (g) and gestational age (wk) were $3170 \pm 420$ and $39.21 \pm 1.29$, respectively. Mean maternal prepregnancy BMI $\left(\mathrm{kg} / \mathrm{m}^{2}\right)$ and maternal gestational weight gain $(\mathrm{kg})$ were $21.8 \pm 3.35$ and $12.7 \pm 3.78$, respectively. Length, head circumference, and body mass assessed at each study point are presented in Table 1 .

A total of 21 total body composition assessments were not performed according to the study protocol, as parents failed to bring their infants for all of the scheduled assessments. A significant number of subjects, being above the PEA POD weight limit of $8 \mathrm{~kg}$ for body composition assessments, failed to complete assessments at 5 and 6 mo of age (Table 1) and therefore, were excluded from data analyses (see Statistical Analysis section).

Table 2 shows the FM and FFM values of girls and boys from birth to 4 mo of age. Data are presented as mean $\pm 2 \mathrm{SD}$.

Table 1. Head circumference (HC), length, and body mass at each study point

\begin{tabular}{ccccc}
\hline & $N$ & HC $(\mathrm{cm})$ & Length $(\mathrm{cm})$ & Body mass $(\mathrm{g})$ \\
\hline Girls & & & & \\
Birth & 23 & $33.98 \pm 1.14$ & $49.22 \pm 2.23$ & $2980 \pm 460$ \\
$2 \mathrm{wk}$ & 30 & $34.80 \pm 0.91$ & $50.97 \pm 1.78$ & $3320 \pm 490$ \\
$1 \mathrm{mo}$ & 35 & $36.19 \pm 1.25$ & $52.72 \pm 2.10$ & $3820 \pm 650$ \\
$2 \mathrm{mo}$ & 35 & $37.90 \pm 1.14$ & $56.33 \pm 2.13$ & $4780 \pm 610$ \\
$3 \mathrm{mo}$ & 32 & $39.28 \pm 1.12$ & $59.53 \pm 2.33$ & $5490 \pm 620$ \\
$4 \mathrm{mo}$ & 28 & $40.41 \pm 1.26$ & $61.57 \pm 2.21$ & $6070 \pm 730$ \\
$5 \mathrm{mo}$ & 23 & $41.31 \pm 1.02$ & $63.67 \pm 1.86$ & $6490 \pm 550$ \\
$6 \mathrm{mo}$ & 12 & $42.34 \pm 0.85$ & $64.48 \pm 2.13$ & $6730 \pm 510$ \\
Boys & & & & \\
Birth & 17 & $34.56 \pm 1.07$ & $49.36 \pm 1.65$ & $3200 \pm 270$ \\
$2 \mathrm{wk}$ & 24 & $35.60 \pm 0.78$ & $52.00 \pm 2.06$ & $3660 \pm 380$ \\
$1 \mathrm{mo}$ & 23 & $37.10 \pm 1.34$ & $54.48 \pm 2.27$ & $4450 \pm 470$ \\
$2 \mathrm{mo}$ & 19 & $38.85 \pm 1.21$ & $58.59 \pm 2.46$ & $5490 \pm 450$ \\
$3 \mathrm{mo}$ & 23 & $40.69 \pm 1.40$ & $61.73 \pm 2.36$ & $6360 \pm 590$ \\
$4 \mathrm{mo}$ & 20 & $41.32 \pm 1.18$ & $63.72 \pm 1.59$ & $6840 \pm 490$ \\
$5 \mathrm{mo}$ & 10 & $42.20 \pm 0.79$ & $66.36 \pm 1.70$ & $7340 \pm 430$ \\
$6 \mathrm{mo}$ & 8 & $43.60 \pm 0.94$ & $68.50 \pm 1.87$ & $7600 \pm 480$ \\
\hline
\end{tabular}

Table 2. FM and FFM at each study point

\begin{tabular}{ccccc}
\hline & $N$ & $\% \mathrm{FM}$ & FM $(\mathrm{g})$ & FFM $(\mathrm{g})$ \\
\hline Girls & & & & \\
Birth & 23 & $8.69 \pm 3.09$ & $260 \pm 120$ & $2710 \pm 380$ \\
$2 \mathrm{wk}$ & 30 & $12.16 \pm 3.60$ & $410 \pm 170$ & $2910 \pm 360$ \\
$1 \mathrm{mo}$ & 35 & $16.12 \pm 5.22$ & $640 \pm 290$ & $3180 \pm 410$ \\
$2 \mathrm{mo}$ & 35 & $22.42 \pm 3.97$ & $1090 \pm 300$ & $3700 \pm 380$ \\
$3 \mathrm{mo}$ & 32 & $25.95 \pm 3.72$ & $1440 \pm 330$ & $4050 \pm 380$ \\
$4 \mathrm{mo}$ & 28 & $27.95 \pm 4.96$ & $1730 \pm 490$ & $4350 \pm 330$ \\
$5 \mathrm{mo}$ & 23 & $29.50 \pm 3.27$ & $1920 \pm 310$ & $4570 \pm 370$ \\
6 mo & 12 & $25.58 \pm 4.51$ & $1730 \pm 390$ & $4990 \pm 270$ \\
Boys & & & & \\
Birth & 17 & $8.94 \pm 2.78$ & $290 \pm 90$ & $2910 \pm 260$ \\
$2 \mathrm{wk}$ & 24 & $12.44 \pm 3.57$ & $460 \pm 150$ & $3200 \pm 300$ \\
$1 \mathrm{mo}$ & 23 & $18.82 \pm 3.77$ & $840 \pm 200$ & $3610 \pm 400$ \\
$2 \mathrm{mo}$ & 19 & $24.69 \pm 3.99$ & $1360 \pm 270$ & $4130 \pm 340$ \\
$3 \mathrm{mo}$ & 23 & $27.25 \pm 4.16$ & $1740 \pm 340$ & $4620 \pm 430$ \\
$4 \mathrm{mo}$ & 20 & $28.28 \pm 4.47$ & $1940 \pm 360$ & $4900 \pm 410$ \\
$5 \mathrm{mo}$ & 10 & $27.47 \pm 2.06$ & $2020 \pm 230$ & $5320 \pm 280$ \\
6 mo & 8 & $28.08 \pm 3.59$ & $2180 \pm 410$ & $5410 \pm 30$ \\
\hline
\end{tabular}

Percentage of FM increased significantly over the first 4 mo of age $(p<0.001)$ both in girls and boys. No differences in \%FM between girls and boys were detected at any study point.

\section{DISCUSSION}

This article presents data related to the body composition changes in a cohort of exclusively breast-fed infants during the first 4 mo of life. The infants enrolled in this study underwent repeated measurements (weekly and monthly testing) of the body composition, providing further insight in the dynamic features of body weight gain and the individual constituents that occur in early life (16-18).

This study reported higher \%FM values at all time points except at birth for both boys and girls and at 1 mo for girls when compared with the study by Fomon et al. (9). When compared with the study by Butte et al. (10), \% FM reported in this study was lower at 3 mo of age. As body composition of breast-fed infants has been reported to be different from formula-fed full-term infants $(19,20)$, the differences in infant feeding modes between the study by Fomon et al. (9), Butte $e t$ al. (10), and our sample may offer a possible explanation for the differences in body composition. However, even when comparing our data with the values reported in the study by Butte et al. (19), which are related only to breast-fed infants, $\% \mathrm{FM}$ of Italian infants was persistently lower both at birth and at 3 mo. The different data reported in this article could be to some extent explained by the fact that Italian infants have a different genetic background that could play an important role in affecting the growth process. In addition, we can hypothesize a role of maternal prepregnancy BMI and gestational weight gain in influencing fetal growth (21). It has been reported that the neonates born to mothers who have a normal pregravid BMI $\left(<25 \mathrm{~kg} / \mathrm{m}^{2}\right)$ have significantly less total and relative fat than the neonates born to overweight/obese mothers (22). Indeed, the mothers of the infants enrolled in this study showed a relative low BMI value.

The variation in FM values between the Italian and US infants could also be because of the composition of breast 
milk in the Italian versus US women might be different because of the different dietary habits $(23,24)$. Nasser et al. (24) reported that the modifications of maternal dietary fat intake lead to quick changes of fatty acids composition of breast milk. Moreover, experimental evidence (23) has shown that polyunsaturated fatty acids of the omega6 series are promoters of the adipose tissue development in vivo during the lactation period.

On the contrary, when comparing our data with the values reported by Eriksson et al. (16), \% FM of Italian infants at 3 mo was similar to that of Swedish infants. This finding could be partially explained by the fact that all the infants studied by Eriksson et al. (16) were delivered by Caucasian women and most of them were exclusively breast fed. In addition, Eriksson et al. (16) assessed body composition using the same device, which is an air-displacement plethysmograph (i.e. PEA POD), as we did in this study.

Early nutrition, growth, and subsequent health are crucially related. Body weight is frequently used as an anthropometrical measure of infant growth. However, it does not provide an accurate assessment of the relative contributions of FM and FFM, which reflect energy deposition and protein storage and represent key indicators of optimal nutritional care. Furthermore, assessment of body composition not only allows optimizing infants' growth and nutritional support but is also helpful for researches exploring the nutritional programming of adult morbidity (1).

This article provides preliminary data on body composition changes, measured by means of an accurate and noninvasive method, in exclusively breast-fed infants during the first months of life. Larger studies are desirable to make a reference body composition data available.

\section{REFERENCES}

1. Barker DJ 1994 Mothers, Babies, and Disease in Later Life. BMJ Publishing, London, United Kingdom

2. Wells JC 2007 The programming effects of early growth. Early Hum Dev 83:743748

3. Barker DJ 1999 Early growth and cardiovascular disease. Arch Dis Child 80:305307
4. Hyppönen E, Kenward MG, Virtanen SM, Piitulainen A, Virta-Autio P, Tuomilehto J, Knip M, Akerblom HK 1999 Infant feeding, early weight gain, and risk of type 1 diabetes. Childhood Diabetes in Finland (DiMe) Study Group. Diabetes Care 22:1961-1965

5. Martorell R, Stein AD, Schroeder DG 2001 Early nutrition and later adiposity. J Nutr 131:874S-880S

6. Stettler N, Kumanyika SK, Katz SH, Zemel BS, Stallings VA 2003 Rapid weight gain during infancy and obesity in young adulthood in a cohort of African Americans. Am J Clin Nutr 77:1374-1378

7. Wells JC, Fewtrell MS 2006 Measuring body composition. Arch Dis Child 91:612617

8. Ellis KJ 2007 Evaluation of body composition in neonates and infants. Semin Fetal Neonatal Med 12:87-91

9. Fomon SJ, Haschke F, Ziegler EE, Nelson SE 1982 Body composition of reference children from birth to age 10 years. Am J Clin Nutr 35:1169-1175

10. Butte NF, Hopkinson JM, Wong WW, Smith EO, Ellis KJ 2000 Body composition during the first 2 years of life: an updated reference. Pediatr Res 47:578-585

11. Agostoni C, Grandi F, Giannì ML, Silano M, Torcoletti M, Giovannini M, Riva E 1999 Growth patterns of breast fed and formula fed infants in the first 12 months of life: an Italian study. Arch Dis Child 81:395-399

12. Dewey KG, Peerson JM, Brown KH, Krebs NF, Michaelsen KF, Persson LA, Salmenpera L, Whitehead RG, Yeung DL 1995 Growth of breast-fed infants deviates from current reference data: a pooled analysis of US, Canadian, and European data sets. Pediatrics 96:495-503

13. World Health Organization 1996 Global Data Bank on Breastfeeding. Breastfeeding: The Best Start. World Health Organization Nutrition Unit, Geneva, Switzerland

14. Ma G, Yao M, Liu Y, Lin A, Zou H, Urlando A, Wong WW, Nommsen-Rivers L, Dewey KG 2004 Validation of a new pediatric air displacement plethysmograph for assessing body composition in infants. Am J Clin Nutr 79:653-660

15. Ellis KJ, Yao M, Shypailo RJ, Urlando A, Wong WW, Heird WC 2007 Bodycomposition assessment in infancy: air-displacement plethysmography compared with a reference 4-compartment model. Am J Clin Nutr 85:90-95

16. Eriksson B, Löf M, Forsum E 2010 Body composition in full-term healthy infants measured with air displacement plethysmography at 1 and 12 weeks of age. Acta Paediatr 99:563-568

17. Rodríguez G, Ventura P, Samper MP, Moreno L, Sarría A, Pérez-González JM 2000 Changes in body composition during the initial hours of life in breast-fed healthy term newborns. Biol Neonate 77:12-16

18. Roggero P, Gianni ML, Orsi A, Piemontese P, Amato O, Moioli C, Mosca F 2010 Neonatal period: body composition changes in breast-fed full term newborns. Neonatology 97:139-143

19. Butte NF, Wong WW, Hopkinson JM, Smith EO, Ellis KJ 2000 Infant feeding mode affects early growth and body composition. Pediatrics 106:1355-1366

20. De Curtis M, Pieltain C, Studzinski F, Moureau V, Gérard P, Rigo J 2001 Evaluation of weight gain composition during the first 2 months of life in breast- and formulafed term infants using dual energy X-ray absorptiometry. Eur J Pediatr 160:319-320

21. Abrams BF, Laros RK Jr 1986 Prepregnancy weight, weight gain, and birth weight. Am J Obstet Gynecol 154:503-509

22. Hull HR, Dinger MK, Knehans AW, Thompson DM, Fields DA 2008 Impact of maternal body mass index on neonate birthweight and body composition. Am J Obstet Gynecol 198:416.e1-416.e6

23. Ailhaud G, Guesnet P 2004 Fatty acid composition of fats is an early determinant of childhood obesity: a short review and an opinion. Obes Rev 5:21-26

24. Nasser R, Stephen AM, Goh YK, Clandinin MT 2010 The effect of a controlled manipulation of maternal dietary fat intake on medium and long chain fatty acids in human breast milk in Saskatoon, Canada. Int Breastfeed J 5:3 